This article is licensed under the Creative Commons Attribution-NonCommercial 4.0 International License (CC BY-NC) (http://www.karger.com/Services/OpenAccessLicense). Usage and distribution for commercial purposes requires written permission.

\title{
Case Series of Inappropriate Concentration of Intraocular Sulfur Hexafluoride
}

\author{
Piotr Kanclerz ${ }^{a} \quad$ Andrzej Grzybowski ${ }^{b, c}$
}

aprivate Practice, Gdańsk, Poland; 'b Department of Ophthalmology, University of Warmia and Mazury, Olsztyn, Poland; 'Institute for Research in Ophthalmology, Foundation for Ophthalmology Development, Poznan, Poland

\section{Keywords}

Expandable gas · Intraocular pressure - Intraocular tamponade · Sulfur hexafluoride ·

Vitrectomy

\section{Abstract}

Due to high complexity, vitreoretinal surgery presents a higher number of patient safety incidents compared with other ophthalmic procedures. Intraocular gases are one of the most useful adjuncts to vitrectomy and surprisingly, surgeons commonly admit to having occasional problems with incorrect gas concentration. The aim of this study is to present a consecutive case series of patients with improper concentration of sulfur hexafluoride $\left(\mathrm{SF}_{6}\right)$ applied during vitrectomy. Three patients underwent 27-gauge vitrectomy and the end of surgery inappropriate dilution of $100 \% \mathrm{SF}_{6}$ was administered. It was attributed to a calculation error, change in the gas supplier, or increased partial pressure of $\mathrm{SF}_{6}$ before dilution. Postoperatively, due to IOP increase, two eyes required intravitreal gas-air exchange. Subsequently, cataract surgery was performed in one eye with concomitant vitrectomy and silicone oil tamponade due to 
retinal detachment. To prevent such complications, we suggest using intraocular gases with great care, training of ophthalmic personnel, and prompting manufacturers to provide $\mathrm{SF}_{6}$ in a prepared concentration of $20 \%$.

(C) 2018 The Author(s)

Published by S. Karger AG, Basel

\section{Introduction}

Intraocular gases are one of the most useful adjuncts in vitreoretinal surgery. Sulfur hexafluoride $\left(\mathrm{SF}_{6}\right)$ has been used as a substitute for air in eyes requiring intraocular tamponade for over 40 years [1]. Complications related to the use of expandable gases include intraocular pressure (IOP) elevation, cataract development, and migration of the gas bubble to the subretinal space or subconjunctivally. The aim of this study was to present a consecutive case series of patients who underwent vitrectomy between November 2015 and December 2017 at the Department of Ophthalmology, Elbląg City Hospital, or the Department of Ophthalmology, Medical University of Gdańsk, Poland, with an inappropriate concentration of $\mathrm{SF}_{6}$ applied.

\section{Case Reports}

Patient data are summarized in Table 1. The first patient presented with an epiretinal membrane, and subsequently underwent vitrectomy with membrane peel in her left eye. As a result of creating an iatrogenic break in the retina intraoperatively, fluid-air exchange was performed. At the end of the surgery the eye was filled with $100 \% \mathrm{SF}_{6}$ instead of the planned concentration of $20 \%$. The reason was the change in gas supplier. The nurse was not properly trained that the new batch of gases was not 20 but $100 \%$, and gave such information to the surgeon without double-checking. On the next day the IOP was $28 \mathrm{~mm} \mathrm{Hg}$, and as it was normalized with topical treatment the patient was discharged from the hospital with topical dorzolamide, timolol, and brimonidine prescribed. Regardless of the administered medications, in the following days the IOP was over $30 \mathrm{~mm} \mathrm{Hg}$. Six days after vitrectomy she underwent an exchange of $5 \mathrm{~mL}$ of intravitreal gas to sterile air. The IOP normalized, and the remaining gas lasted in the vitreous cavity for about 2 weeks. Due to the development of a cataract, the patient underwent phacoemulsification cataract surgery 2 months later.

The second patient had an uneventful vitrectomy for epiretinal membrane and macular hole. However, he received $40 \% \mathrm{SF}_{6}$ instead of the intended $20 \%$ concentration. A mistake in calculation took place, which was revealed by the assistant after the surgery; $20 \mathrm{~mL}$ of $100 \%$ $\mathrm{SF}_{6}$ was taken into a $50-\mathrm{mL}$ syringe and subsequently diluted to $50 \mathrm{~mL}$ with sterile air, with a final concentration of $40 \%$. Properly done, $10 \mathrm{~mL}$ of $\mathrm{SF}_{6}$ should be exhausted and the remaining $10 \mathrm{~mL}$ should be diluted to $50 \mathrm{~mL}$ with sterile air, achieving the concentration of $20 \%$. Nevertheless, the IOP following vitrectomy was normal.

The third patient, a 67-year-old woman, presented with a stage IV full-thickness macular hole in her left eye. She underwent 23-gauge vitrectomy with internal limiting membrane peeling and $20 \% \mathrm{SF}_{6}$ tamponade. As a result of nonclosure of the macular hole, she decided to undergo a second vitrectomy after 16 months. A 27-gauge vitrectomy was performed with removal of the remnants of the internal limiting membrane, draining of fluid from the macular 


\section{Case Reports in Ophthalmology}

Case Rep Ophthalmol 2018;9:405-410

DOI: $10.1159 / 000492746$

(c) 2018 The Author(s). Published by S. Karger AG, Basel www.karger.com/cop

Kanclerz and Grzybowski: Inappropriate Concentration of Intraocular Sulfur Hexafluoride

hole, fluid air exchange, and administration of a $20 \% \mathrm{SF}_{6}$ compound. After the surgery the patient complained of a severe headache and nausea, with the IOP reaching $45 \mathrm{~mm} \mathrm{Hg}$. With intravenous mannitol, topical dorzolamide, timolol, and brimonidine the IOP decreased to 38 $\mathrm{mm} \mathrm{Hg}$; however, the pain sustained. Two days after vitrectomy the surgeon in charge decided to perform a gas-air exchange. Although the IOP lowered, the eye fundus examination revealed retinal detachment with an iatrogenic retinal tear. Two days later the patient underwent phacovitrectomy and the eye was filled with 1,000 cSt of silicone oil. The reason for the unexpected gas expansion cannot be confirmed. The IOP was increased primarily in an open-angle mechanism. Pathology of the lens-iris diaphragm was excluded at all stages, and the patient had no complications in the primary vitrectomy with $20 \% \mathrm{SF}_{6}$ tamponade. It is presumed that increased gas expansion was due to unanticipated $\mathrm{SF}_{6}$ concentration, when $10 \mathrm{~mL}$ of $\mathrm{SF}_{6}$ from a large tank of $125 \mathrm{~g}$ was taken into a 50 -mL syringe through a reducer. Although $\mathrm{SF}_{6}$ was diluted to $50 \mathrm{~mL}$ with sterile air, the pressure of the $\mathrm{SF}_{6}$ in the syringe, and the final concentration of the gas could not be determined. Slit lamp examination of a patient with significant IOP increase after $\mathrm{SF}_{6}$ tamponade is demonstrated in Figure 1.

\section{Discussion and Conclusions}

Elevated IOP after vitrectomy may cause optic nerve damage, retinal ischemia, and subsequent visual loss. If a $30 \% \mathrm{SF}_{6}$ tamponade is applied, up to $20.4 \%$ of patients might experience IOP over $30 \mathrm{~mm} \mathrm{Hg}$ on postoperative day 1 [2]. The risk of increased IOP is associated with expansile gas concentration, concomitant circumferential scleral buckling, and patients' age [3]. $\mathrm{SF}_{6}$ is supplied within different concentrations ranging from 20 to $100 \%$. Single- or multiple-use systems are available, in low- or high-pressure containers with reducers. In practice, the final concentration used during vitrectomy is at the surgeon's discretion, ranging from 18 to $30 \%$; for example, in the UK a $20 \%$ compound is most commonly applied [4]. A $100 \%$ concentration of $\mathrm{SF}_{6}$ is used for retinal detachment pneumatic retinopexy [5], displacement of submacular hemorrhages secondary to choroidal neovascular membrane, and retinal arterial macroaneurysm [6]. In recent years the preference for retinal detachment repair shifted among surgeons toward vitrectomy with a decline in pneumatic retinopexy; thus $100 \% \mathrm{SF}_{6}$ is used less frequently [7]. Although uncomplicated vitreoretinal procedures with normal preoperative IOP and no gas tamponade are unlikely to have uncontrolled IOP [2], one should not attribute postoperative IOP spikes solely to inappropriate gas concentration. Other common reasons include postoperative inflammation and angiogenic, steroid-induced, and blood-mediated mechanisms [8].

Due to high complexity, vitreoretinal surgery results in a higher number of patient safety incidents compared with other ophthalmic procedures [9]. Furthermore, a large percentage of diseases managed by vitreoretinal specialists have potential for severe visual impairment or blindness, thus presenting a risk for malpractice litigation [10]. The described cases highlight the danger associated with use of concentrated $\mathrm{SF}_{6}$ to the patients' visual function. A case of inappropriate percentage and volume of gas injected into an eye having a concurrent scleral buckling procedure was reported recently [9]. Surprisingly, vitreoretinal surgeons commonly admit to having occasional problems with incorrect gas concentration. 
When faced with high IOP due to an enlarging gas bubble a treatment option is to tap the gas in the outpatient clinic. Intravenous mannitol is known to work suboptimally in vitrectomized eyes. The increase in IOP in the presented cases cannot be attributed to sclerotomy suturing, and an advantage of nonsuturing is allowing a free passage of air/gas if IOP is elevated. However, leaving leaking sclerotomies unsutured can result in hypotony and attendant complications. Another solution for preventing the aforementioned complications is using intraocular gases with great care and training of ophthalmic personnel in their proper application. This should be employed in every setting, although it is not possible to completely eliminate human errors. Thus, another concept would be prompting the manufacturers to provide $\mathrm{SF}_{6}$ solely in a prepared concentration of $20 \%$.

\section{Statement of Ethics}

The authors have no ethical conflicts to disclose.

\section{Disclosure Statement}

The authors declare that they have no competing interests. Dr. Kanclerz reports nonfinancial support from Visim. Dr. Grzybowski reports grants, personal fees, and nonfinancial support from Bayer, nonfinancial support from Novartis, Alcon, Thea, and Santen, and personal fees and nonfinancial support from Valeant, outside the submitted work. No funding has been received for this study.

\section{References}

1 Norton EW. Intraocular gas in the management of selected retinal detachments. Trans Am Acad Ophthalmol Otolaryngol. 1973 Mar-Apr;77(2):OP85-98.

2 Wong R, Gupta B, Williamson TH, Laidlaw DA. Day 1 postoperative intraocular pressure spike in vitreoretinal surgery (VDOP1). Acta Ophthalmol. 2011 Jun;89(4):365-8.

3 Chen TC: Risk factors for intraocular pressure elevations after pupillary dilation in patients with open angles. Ann Ophthalmol 2005;37:69-76.

4 Kontos A, Tee J, Stuart A, Shalchi Z, Williamson TH. Duration of intraocular gases following vitreoretinal surgery. Graefes Arch Clin Exp Ophthalmol. 2017 Feb;255(2):231-6.

5 Assi A, Gregor Z. The use of intravitreal gases in non-vitrectomised eyes. Eye (Lond). 2001 Aug;15(Pt 4):497-506.

6 Abdelkader E, Yip KP, Cornish KS. Pneumatic displacement of submacular haemorrhage. Saudi J Ophthalmol. 2016 Oct-Dec;30(4):221-6.

7 McLaughlin MD, Hwang JC. Trends in Vitreoretinal Procedures for Medicare Beneficiaries, 2000 to 2014. Ophthalmology. 2017 May;124(5):667-73.

8 Costarides AP, Alabata P, Bergstrom C. Elevated intraocular pressure following vitreoretinal surgery [v.]. Ophthalmol Clin North Am. 2004 Dec;17(4):507-12.

9 Wong SC, Kelly SP, Sullivan PM. Patient safety in vitreoretinal surgery: quality improvements following a patient safety reporting system. Br J Ophthalmol. 2013 Mar;97(3):302-7.

10 Kraushar MF. Medical malpractice experiences of vitreoretinal specialists: risk prevention strategies. Retina. 2003 Aug;23(4):523-9. 


\section{Case Reports in Ophthalmology}

Case Rep Ophthalmol 2018;9:405-410

(c) 2018 The Author(s). Published by S. Karger AG, Basel www.karger.com/cop

Kanclerz and Grzybowski: Inappropriate Concentration of Intraocular Sulfur Hexafluoride

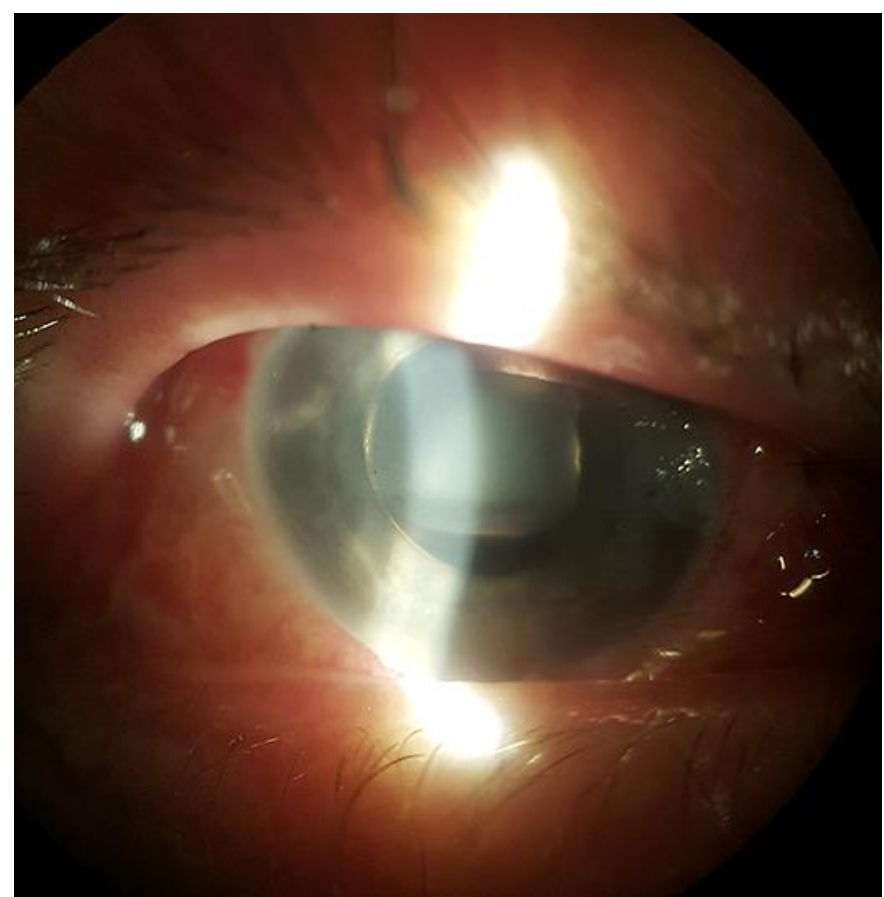

Fig. 1. Slit lamp examination of a patient with significant intraocular pressure increase after $\mathrm{SF}_{6}$ tamponade. Ballooning of the bulbar conjunctiva, corneal edema, and diffuse shallowing of the anterior chamber is observed (photo by the author). 
Table 1. Summary of patient data

\begin{tabular}{|c|c|c|c|c|c|c|c|}
\hline Patient & $\begin{array}{l}\text { Age, } \\
\text { years }\end{array}$ & Sex & Diagnosis & $\begin{array}{l}\text { Vitrectomy } \\
\text { gauge }\end{array}$ & $\begin{array}{l}\text { Sclerotomies } \\
\text { sutured }\end{array}$ & $\begin{array}{l}\text { Planned } \mathrm{SF}_{6} \\
\text { concentration }\end{array}$ & $\begin{array}{l}\text { Final } \mathrm{SF}_{6} \\
\text { concentration }\end{array}$ \\
\hline 1 & 65 & female & $\begin{array}{l}\text { epiretinal } \\
\text { membrane, } \\
\text { intraoperative } \\
\text { retinal break }\end{array}$ & 27 & $2 / 3$ & $20 \%$ & $100 \%$ \\
\hline 2 & 60 & male & $\begin{array}{l}\text { epiretinal mem- } \\
\text { brane, } \\
\text { macular hole }\end{array}$ & 27 & $1 / 3$ & $20 \%$ & $40 \%$ \\
\hline 3 & 67 & female & $\begin{array}{l}\text { unclosed } \\
\text { macular hole }\end{array}$ & 27 & $3 / 3$ & $20 \%$ & unknown \\
\hline
\end{tabular}

$\mathrm{SF}_{6}$, sulfur hexafluoride. 